\title{
The Morphological Variability of Neuromuscular Junctions in the Rat Extraocular Muscles : A Scanning Electron Microscopical Study*
}

\author{
Junzo DESAKI \\ Department of Anatomy, Ehime University School of Medicine, Shigenobu, Ehime, Japan \\ Received November 6, 1989
}

Summary. Six morphologically distinct types of neuromuscular junctions were identified by scanning electron microscopy in the rat extraocular muscles: two diffuse and four focal types.

The diffuse junctions, spreading out extensively over the muscle fiber surface, were characterized by two types of varicose swellings (or terminal varicosities) of nerve endings. One type consisted of several ramifying nerve endings and shallow postsynaptic depressions with poorly-developed junctional folds. The other type consisted of a single axon and formed many synaptic contacts along the long axis of a muscle fiber. Round synaptic depressions facing the varicosities contained several junctional folds. The focal junctions, confined to an oval area on the muscle fiber surface, were characterized by the complexity and variability of their subneural apparatuses. Four different types of apparatuses, i.e., focal junctions, were found: 1) an apparatus consisting of labyrinthine gutters with numerous slitlike junctional folds, 2) apparatuses consisting of a large number (more than 20) of cup-like depressions with either a small number of pit-like junctional folds or 3) numerous slit-like ones, and 4) an apparatus consisting of a small number (about 10) of cup-like depressions with a few junctional folds.

The findings indicate that the rat extraocular muscles contain six different types of muscle fibers.

Muscle fibers of rat extraocular muscles have been classified into six different types according to the differences in their diameters, enzymatic activities and ultrastructural features (MAYR, 1971). On the other hand, the innervation patterns of the same muscles have also exhibited a morphological diversity both in light microscopical histochemistry for acetylcholinesterase (AChE) activity and in transmission electron microscope (TEM) studies; to date, one type of motor endplate and two types of multiple endings have been demonstrated (TERÄVÄINEN, 1968). There has been a great controversy over the classification of muscle fibers and the morphological variability of neuromuscular junctions.

By removal of the intramuscular connective tissue and basal laminae by $\mathrm{HCl}$-hydrolysis, we (DESAKI and UEHARA, 1981, 1987) previously demonstrated with the scanning electron microscope (SEM), the morphological variability of skeletal neuromuscular junctions between animal species and the developmental process of subneural apparatuses at the junctions in postnatal rats. This specimen preparation serves to clarify the overall morphology of the junctions.

The present SEM study demonstrates the morphological variability of the junctions in the rat extraocular muscles using the $\mathrm{HCl}$-hydrolysis method, paying particular attention to the threedimensional organization of the subneural apparatuses.

\section{MATERIALS AND METHODS}

Six extraocular muscles (four recti and two obliqui) of 3-month-old albino rats (Wistar), weighing about $360 \mathrm{~g}$, were used in the present study. These have been shown to contain similar fiber populations (PEAChey, 1971; Chang-Minoda and Sato, 1973; DurSTON, 1974; RINGEL et al., 1978a, b).

After the animals were anaesthetized with ether, the muscles were dissected out to be cut into small

*This work was supported in part by a grant from the Ministry of Education, Science and Culture, Japan. 
strips of about $2 \times 1 \times 1 \mathrm{~mm}$. The procedure for SEM was the same as described elsewhere (DESAKI and UEHARA, 1981, 1987). The specimens were examined in a Hitachi S-500A scanning electron microscope.

\section{RESULTS}

Two groups of neuromuscular junctions were observed in the rat extraocular muscles, characterized by their size, distribution and three-dimensional morphology. The first group, spreading out extensively over the muscle fiber surface in the distal third of the muscle, will here be tentatively called the "diffuse junction", for the purpose of distinguishing it from the other group. The other group, more or less confined to an oval area on the muscle fiber surface near the middle of the muscle, will therefore be called the "focal junction".

\section{Diffuse neuromuscular junctions}

Two types of diffuse junctions were clearly distinguished. In one type, the nerve endings ramified into several (2-5) branches less than $1 \mu \mathrm{m}$ in diameter before the formation of neuromuscular contacts with the muscle fiber about $10-15 \mu \mathrm{m}$ in diameter; they were irregularly distributed with respect to the muscle fibers, which partly appeared to overlap each other (large type) (Fig. 1a). They were characterized by several small varicose swellings (or terminal varicosities) $2-3 \mu \mathrm{m}$ in diameter. After removal of the nerve endings, the junctional sarcolemma exhibited shallow, round depressions with a small number of poorly-developed junctional folds (Fig. 1b).

In the other type of diffuse junction (small type), the nerve endings consisted of a single axon. They were characterized by their beaded appearance with $10-20$ or more terminal varicosities (about $2-3 \mu \mathrm{m}$ in diameter) and thin intervaricose strands (about $1 \mu \mathrm{m}$ in diameter) along the long axis of an extremely small muscle fiber about $5-10 \mu \mathrm{m}$ in diameter (Fig. $2 a)$. The distance between terminal varicosities was rather variable, ranging from 5 to $30 \mu \mathrm{m}$. The junctional sarcolemma facing the terminal varicosities consisted of simple, shallow, round depressions about $2-3 \mu \mathrm{m}$ in diameter (Fig. $2 \mathrm{~b}$ ). Several slit-like and pit-like junctional folds were found in the depressions (Fig. 2b, inset). The nerve endings of the two diffuse junctions were deriverd from nonmyelinated stem nerves.

\section{Focal neuromuscular junctions}

Four morphologically different types of focal junctions were distinguished mainly by the differences in the organization of the subneural apparatuses, including the developmental degree of junctional folds.

One of the four focal junctions consisted of a number of thin, ramifying nerve endings $2-3 \mu \mathrm{m}$ in diameter, which often appeared to overlap and join each other to form a rather complicated texture on the muscle fibers which were about $15-25 \mu \mathrm{m}$ in diameter (type 1) (Fig. 3a). After removal of the nerve endings, the apparatuses exhibited deep and irregular labyrinthine synaptic gutters about $2 \mu \mathrm{m}$ wide; these were incompletely partitioned by ridges or folds of the junctional sarcolemma (Fig. 3b). The synaptic gutters contained a number of slit-like junctional folds (about $0.1-0.2 \mu \mathrm{m}$ wide and $0.2-1.0 \mu \mathrm{m}$ long), although they concomitantly contained a small number of pit-like ones. The junctional folds were randomly disposed with respect to the long axis of the muscle fibers.

A second type of focal junction (type 2) consisted of thin ramifying nerve endings less than $2 \mu \mathrm{m}$ in diameter, which were characterized by terminal varicosities $(2-5 \mu \mathrm{m}$ in diameter) on the muscle fibers about $10-20 \mu \mathrm{m}$ in diameter. Its apparatus, different from the labyrinthine gutters (see Fig. 3b), consisted of many (more than 20) cup-like depressions (2-5 $\mu \mathrm{m}$ in diameter) (Fig. 4). Individual depressions contained a small number of pit-like or elongated oval (about 0 . $1 \mu \mathrm{m}$ wide and $0.1-0.5 \mu \mathrm{m}$ long) junctional folds.

A third type of focal junction (type 3 ) showed an almost identical texture to the type 2 focal one and was found on the surface of muscle fibers about 10-20

Fig. 1. SEM images of the large type of diffuse junction. a. This large type consists of several thin ramifying nerve endings characterized by terminal varicosities (arrows). $\times 2,100$. b. Synaptic depressions (arrows) facing terminal varicosities are shallow and contain poorly-developed junctional folds. $\times 3,300$

Fig. 2. SEM images of the small type of diffuse junction. a. This small type is characterized by a nerve ending with varicosities (arrows) along the long axis of an extremely small muscle fiber. $\times 1,700$. b. Individual synaptic depressions (arrows) facing the varicosities show a simple round cup-like profile. $\times 3,700$. Inset: Higher magnification of a cup-like depression. Note the existence of several junctional folds. $\times 5,000$ 

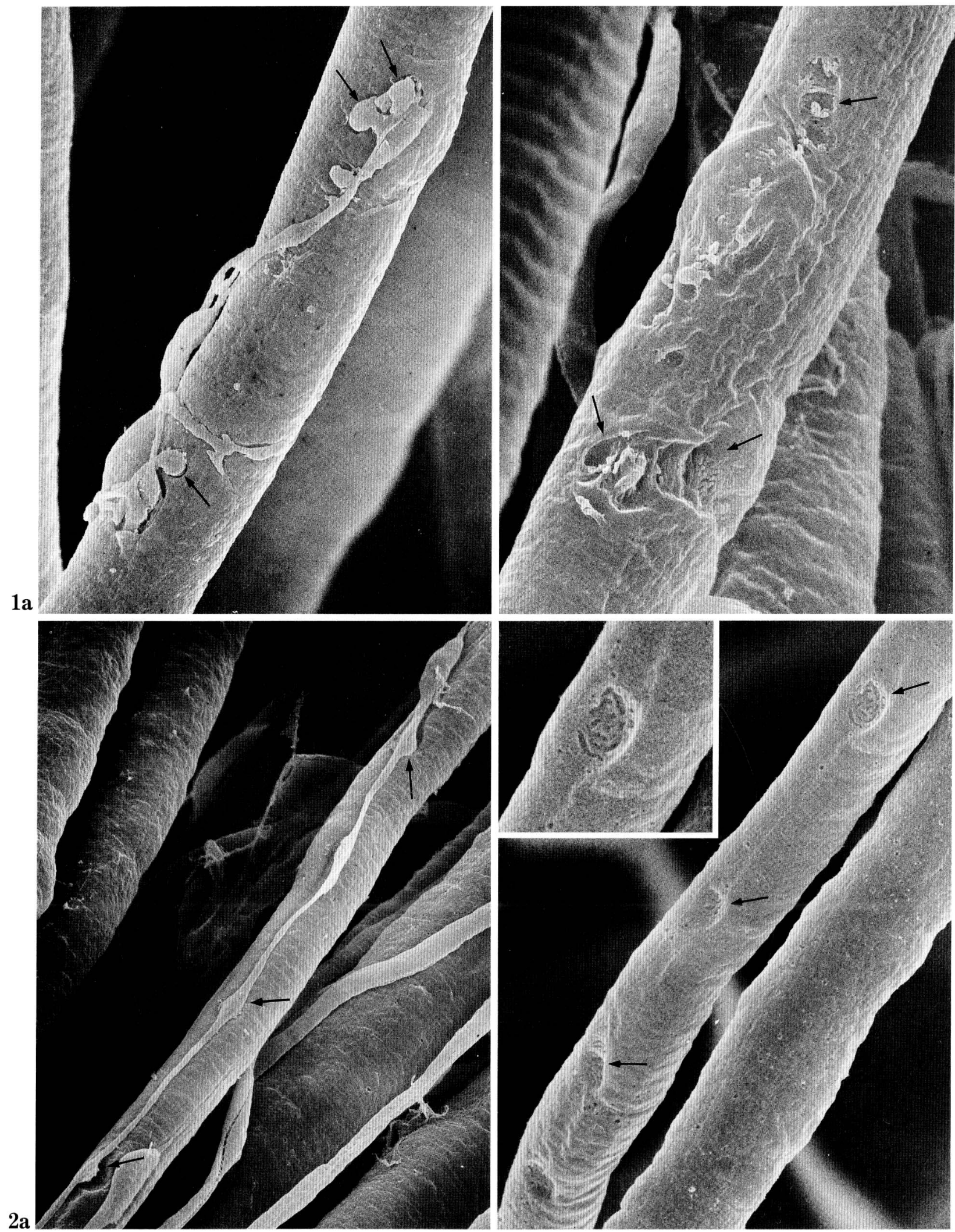

Figs. 1 and 2. Legends on the opposite page. 

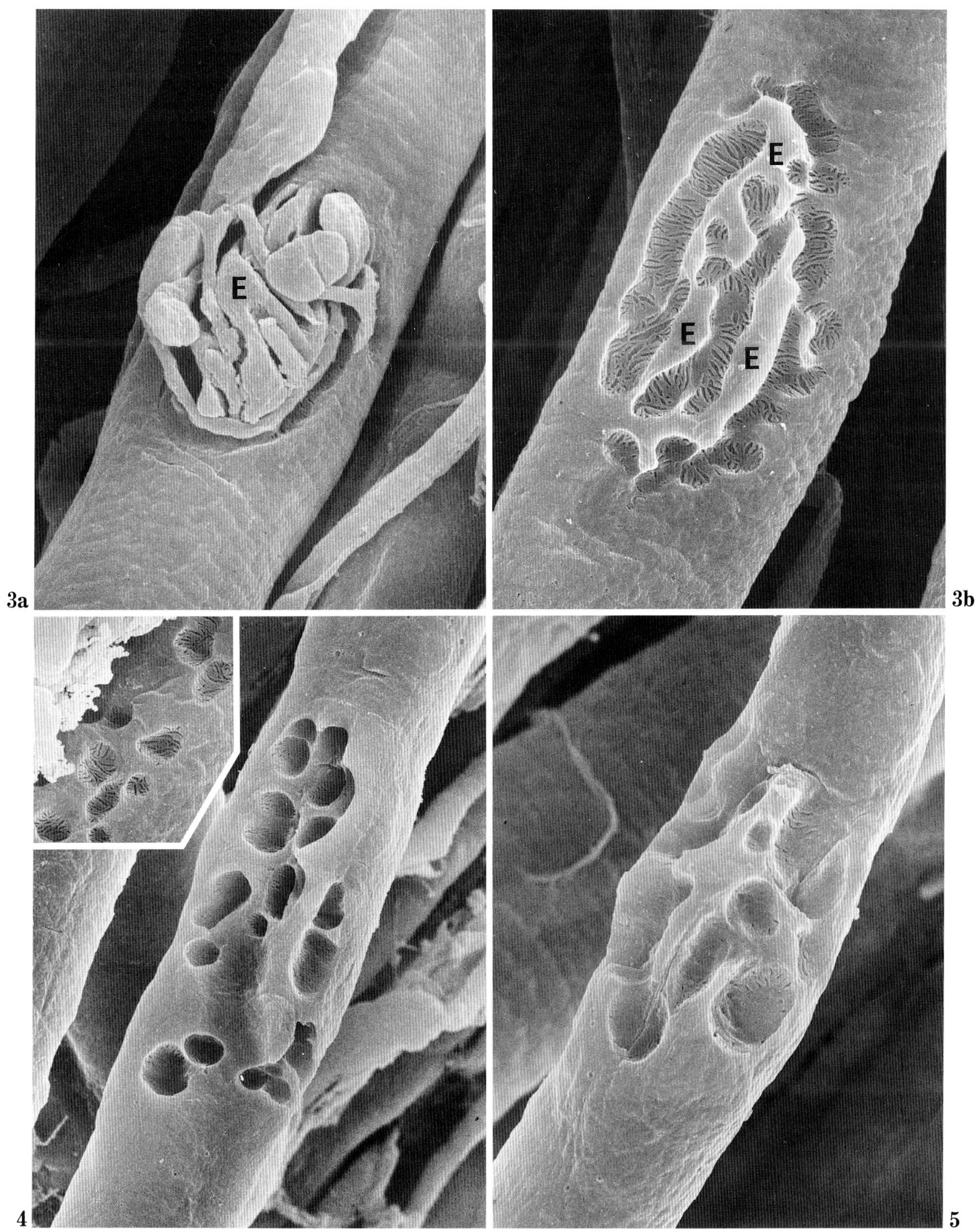

Figs. 3-5. Legends on the opposite page. 
$\mu \mathrm{m}$ in diameter. However, the depressions contained a number of predominantly slit-like junctional folds (Fig. 4, inset).

A fourth type of focal junction (type 4) was similar to, but smaller than the type 2 focal one and was confined to extremely small muscle fibers about 5-10 $\mu \mathrm{m}$ in diameter. Its apparatus consisted of a small number of cup-like depressions about $2-5 \mu \mathrm{m}$ in diameter (Fig. 5). There were about 10 depressions per junction. Individual depressions contained a small number of pit-like or elongated oval junctional folds. The nerve endings of the four focal junctions were derived from myelinated stem nerves.

\section{DISCUSSION}

The present SEM study has demonstrated the existence of six different types of neuromuscular junctions in the rat extraocular muscles: two diffuse and four focal types. We propose the terms of diffuse and focal junctions instead of multiple nerve terminals and single motor endplates respectively, on the basis of the overall morphology of the junctions observed by SEM.

Two types of diffuse junctions in the present SEM study basically appear to correspond to two types of multiple terminals previously reported with histochemical staining for AChE activity and with TEM in the rat extraocular muscles (TERÄVÄINEN, 1968): one type of multiple terminal (large type) consisting of a few nerve endings and weakly-developed secondary synaptic clefts, and the other (small type) consisting of numerous smaller terminals and poorlydeveloped secondary synaptic clefts. In the mouse (SAlPeTER et al., 1974; KACZMARSKI, 1974; PACHTER et al., 1976) and sheep (HARKER, 1972) extraocular muscles, only one type of multiple neuromuscular junction has been reported, using serial thin sectioning. PACHTER et al. (1976) demonstrated in the mouse that the multiple junctions display varying degrees of complexity from different regions of the same muscle fiber; one is virtually flat, while the other suggests a marked depth of postjunctional folding which may also occur on these so-called 'en grappe' endings. However, the diffuse junctions in the rat do not seem to show junctional complexity along their lengths. Two types of diffuse junctions, compared with the focal ones, were derived from unmyelinated nerve axons which either make synaptic contacts along their course with the muscle fiber at a variable distance (small type); or these terminals were grouped closely together (large type), and were apposed only to muscle fibers with slow contractions (TERÄVÄINEN, 1968).

On the other hand, TERÄVÄINEN (1968) has reported in the rat extraocular muscles only one type of focal junction having numerous junctional folds. OGATA (1988) has recently demonstrated some SEM images of the motor endplates, but they seem to be unavoidably unclear owing to the incomplete removal of the intramuscular connective tissue by the $\mathrm{HCl}$ hydrolysis method. We confirmed in the present SEM study that the rat extraocular muscles contained at least four different types of focal junctions. The type 1 focal junction, consisting of the apparatus with deep labyrinthine gutters which contain numerous slit-like junctional folds, shows almost all the same SEM appearance as that in mammalian skeletal muscles (DESAKI and UEHARA, 1981, 1987; FAHIM et al., 1983; OGATA and YAMASAKI, 1985; MATSUDA et al., 1988). It seems to be commonly found in all mammalian skeletal muscles.

The other three types of focal junctions, more or less characterized by the apparatuses with a group of cup-like depressions, show a similar SEM profile to those described in the avian muscles (DESAKI and UEHARA, 1981). Recent TEM studies of the extraocular muscles in the monkey (MILlER, 1971), sheep (HARKER, 1972) and mouse (SALPETER et al., 1974; PACHTER et al., 1976) have reported that a

Fig. 3. SEM images of a type 1 focal junction. a. This type shows a complicated texture consisting of a number of thin ramifying nerve endings. $E$ sarcoplasmic elevation. $\times 3,100$. b. The subneural apparatus consists of irregular labyrinthine gutters which are partitioned by ridges or folds of the junctional sarcolemma, containing numerous slit-like junctional folds. $E$ Sarcoplasmic elevations. $\times 3,500$

Fig. 4. The subneural apparatus of a type 2 focal junction, consisting of a group of round depressions of more than 20 per junction. Each depression contains a small number of junctional folds, showing an almost pit-like or elongated oval profile. $\times 2,100$. Inset: The subneural apparatus of a type 3 focal junction. Each depression contains numerous slit-like junctional folds. $\times 2,400$

Fig. 5. The subneural apparatus of a type 4 focal junction, consisting of a small number of cup-like depressions which contain a few pit-like or elongated oval junctional folds. $\times 3,500$ 
certain type of motor endplate was characterized by large and widely diffuse nerve endbulbs and by sparser junctional folds. This type of motor endplate, which has been designated as a single diffuse ending or a diffuse single endplate, corresponds to the type 2 focal junction of the present SEM study.

The type 4 focal junction, consisting of a smaller aggregation of cup-like depressions, appears to correspond to the thin sole plates with rare junctional folds on the small fibers shown by TEM in the sheep (HARKER, 1972) and mouse (PACHTER et al., 1976). These three types (types 1, 2 and 4) of focal junctions have been found in the sheep (HARKER, 1972) and mouse (PACHTER et al., 1976).

However, the type 3 focal junction, consisting of a group of cup-like depressions with numerous slit-like folds, has not yet been reported. It appears to represent an "intermediate" form between the type 1 and the type 2 focal junctions. This type 3 focal junction is not necessarily distinguishable from the type 1 focal one in the thin sectional profiles. It therefore seems to be a new type of junction in the mammalian extraocular muscles.

The present SEM study suggests that the rat extraocular muscles contain six different types of muscle fibers innervated by each kind of motor nerve: two diffusely innervated and four focally innervated fibers. In the extraocular muscles of mammalian species, the existence of at least five morphologically different types of muscle fibers is now widely accepted. This view is supported by the discrimination of single versus multiple innervation, as well as by the characteristics of internal cell structure and topographical distribution (e.g. global and orbital layers) of the respective fiber population within the muscle: two multiply innervated and three singly innervated fibers in the cat (PEACHEY et al., 1974; AlvarADO and VAN HORN, 1975) and mouse (PACHTER et al., 1976); two multiply innervated and four singly innervated fibers in the rat (MAYR, 1971) and monkey (PACHTER, 1982); and three multiply innervated and three singly innervated fibers in the sheep (HARKER, 1972). However, the relationship between the morphology of the neuromuscular junctions and the classification of muscle fibers has not been completely clarified. Further studies, including reconstructions from serial thin sections while paying particular attention to the topograhical distribution of each different type of muscle fiber, are needed to precisely determine the relationship between them.

\section{REFERENCES}

Alvarado, J. A. and C. Van Horn: Muscle cell types of the cat inferior oblique. In: (ed. by) G. LENNERSTRAND and P. BACH y RiTA: Basic mechanism of ocular motility and their clinical implications. Pergamon Press, Oxford, 1975 (p. 15-43).

Cheng-Minoda, K. and Y. Sato: Distribution of twitch and slow fibers in extraocular muscles. Jap. J. Ophthalmol. 17: 2-10 (1973).

DeSaKI, J. and Y. Uehara: The overall morphology of neuromuscular junctions as revealed by scanning electron microscopy. J. Neurocytol. 10: 101-110 (1981).

: Formation and maturation of subneural apparatuses at neuromuscular junctions in postnatal rats: A scanning and transmission electron microscopical study. Devel. Biol. 119: 390-401 (1987).

DuRston, J. H. J.: Histochemistry of primate extraocular muscles and the changes of denervation. Brit. J. Ophthal. 58: 193-216 (1974).

FaHim, M. A., J. A. Holley and N. RobBins: Scanning and light microscopic study of age changes at a neuromuscular junction in the mouse. J. Neurocytol. 12:13-25 (1983).

HARKER, D. W.: The structure and innervation of sheep superior rectus and levator palpebrae extraocular muscles. I. Extrafusal muscle fibers. Invest. Ophthalmol. 11: 956-969 (1972).

KaCzMARSKI, F.: Motor end-plates in the extraocular muscles of small mammals. Acta Anat. 89: 372-386 (1974).

Matsuda, Y., S. OKI, K. Kitaoka, Y. Nagano, M. NoJima and J. Desaki: Scanning electron microscopic study of denervated and reinnervated neuromuscular junction. Muscle Nerve 11: 1266-1271 (1988).

MAYR, R.: Structure and distribution of fiber types in the external eye muscles of the rat. Tiss. Cell 3: 433-462 (1971).

MilLER, J. E.: Recent histologic and electron microscopic findings in extraocular muscle. Trans. Amer. Acad. Ophthalmol. Otolar. 75: 1175-1185 (1971).

OGATA, T.: Structure of motor endplates in the different fiber types of vertebrate skeletal muscle. Arch. Histol. Cytol. 51: 385-424 (1988).

OGATA, T. and Y. Yamasaki: The three-dimensional structure of motor endplates in different fiber types of rat intercostal muscle. Cell Tiss. Res. 241: 465-472 (1985).

Pachter, B.: Fiber composition of the superior rectus extraocular muscle of the Rhesus macaque. J. Morphol. 174: 237-250 (1982).

Pachter, B. R., J. Davidowitz and G. M. Breinin: Light and electron microscopic serial analysis of mouse extraocular muscle: Morphology, innervation and topographical organization of component fiber populations. Tiss. Cell 8: 547-560 (1976). 
Peachey, L. D.: The structure of extraocular muscle fibers of mammals. In: (ed. by) P. BACH y RiTA, C. C. Collins and J. E. HYDE: The control of eye movements. Vol. II, Academic Press, New York, 1971 (p. 47-66).

Peachey, L. D., M. Takeuchi and A. C. NAg: Muscle fiber types and innervation in adult cat extraocular muscle. In: (ed. by) A. T. Milharat: Exploratory concepts in muscular dystrophy. Excerpta Medica, Amsterdam, 1974 (p. 246-254).

Ringel, S. P., W. K. Engel, A. N. Bender, N. D. Peters and R. D. Yee: Histochemistry and acetylcholine receptor distribution in normal and denervated monkey extraocular muscles. Neurol. 28: 55-63 (1978a).

Ringel, S. P., W. B. Wilson, M. T. Barden and K. K. KAISER: Histochemistry of human extraocular muscle. Arch. Ophthalmol. 96: 1067-1072 (1978b).

Salpeter, M. M., F. A. MChenRy and H. Feng: Myoneural junctions in the extraocular muscles of the mouse. Anat. Rec. 174: 201-224 (1974).
TeräväInen, H.: Electron microscopic and histochemical observations on different types of nerve endings in the extraocular muscles of the rat. Z. Zellforsch. 90: 372-388 (1968).

Dr. Junzo DESAKI Department of Anatomy, Ehime University School of Medicine, Shigenobu, Ehime 791-02 Japan

出 崎 順三 791-02 愛媛県温泉郡重信町志津川 愛媛大学医学部 第二解剖学教室 